\title{
ANTHROPOLOGICAL STUDY OF KERMAN CARPET SYMBOLS, SHAPES, AND DESIGNS
}

\author{
Dr. Yaghoub Sharbatian \\ Assistant Professor of Anthropology \\ Islamic Azad University, Garmsar Branch, Garmsar, Iran \\ E-mail: dy_sharbatian@yahoo.com \\ Roya Bagheri \\ PhD Student of Anthropology \\ Islamic Azad University, Central Tehran Branch, Iran \\ E-mail: RoyaBagheri1989@yahoo.com
}

\begin{abstract}
Different traditional Iranian art forms can be known as a single semantic recreation in different forms. All of them imply some shared concepts which are a mix of Persian and Islamic beliefs. These arts have a symbolic tone and the artist speaks through their art using the appropriate allegorical tools. In this field, the Kerman carpet should be known as an excellent manifestation of symbols and mysterious designs that are eloquently implemented on the carpet. The purpose of this study is the anthropological analysis of the symbols, designs, and patterns used in the Kerman carpet as well as the analysis of the Kermanian people's beliefs based on those designs and symbols. The research method used here is the Qualitative type and in the form of ethnographic, and also the information are collected using interview-participation and documents. The theoretical framework of this study is based on Clifford Geertz's Symbolic-Interpretive Anthropology Approach theory. The findings of this study show that the Kerman carpet alongside its beauty and charm includes meaningful designs and patterns and these designs and symbols are derived from the geographical-cultural and social area and are connected with the everyday life, traditions, and beliefs of the people of their area.
\end{abstract}

Keywords: Anthropology, Design, Kerman Carpet, Shape, Symbol.

\section{Introduce the Problem}

\section{INTRODUCTION}

Iran, the cradle of carpets in the world, has had the universal fame of being the land of carpets for a long time and there are still thousands upon thousands of exquisite rugs and carpets available from Iran's carpet viewing poles to its enthusiasts. Carpet creation in different regions of Iran is dependent on beliefs and traditions or in other words culture, the wavers' mental states, and also geographic location. Weavers of each area weave carpets with inspiration from their history and traditions. Iranian carpets are a two-dimensional commodity, with one dimension of it being art and the other industry. The existence of these two dimensions has helped this industry to retain its magnificence and beauty. 
The carpet is a live and telling art which shows the heart and spiritual purity of the weaver. Is it an art whose pattern talks to the human soul? All these hand-woven creations are representations of a greater and more valuable subject and show us the paths of the old, which can elaborate on the weaver's emotion in different situations. Also, it clears many symbols and signs for us. Also, other symbols and patterns of them can be a representation of tradition and civilization of any ethnicity. When we look at the themes of these hand-woven carpets we see that they represent the history of Iranian art and culture. These carpets are mirror-like displays and retell all aspects of the life of any people. Because carpets have applied as well as aesthetic aspects, they can be analyzed in terms of external and internal form as well as their decorative motifs and colors. Based on this, in this study researchers are looking to answer the question that from the perspective of anthropology which symbols and designs are available in the Kerman carpet that based on analysis can lead to their people's culture and customs.

\section{Explore Importance of the Problem}

Carpets have always been one of the fundamental furniture pieces of each Persian household and skill in Carpet-weaving is almost one of Iranian's national characteristics. The art of Carpetweaving is rooted in society because it has had risen from the heart of society and people. Then it's completely clear that this kind of art has a relationship with people's everyday life and is a kind of reflection from social life, culture, and thought type of people of different ages; If we want to analyze the behavior, beliefs, thoughts, and insights of the people of a society we should look no further than this art form and it is only then that we could find some hidden truths. Based on this, the pictures, designs, and signs available on each carpet can help us to identify and recognize the people of each period. These hand woven carpets are firm ancient traditions that carry many beliefs with their warp and woof which were respected among people from the old times and some of those traditions were preserved and were transferred generation by generation. Of course in recent years, having a connection to the past and ancient traditions are rarer because of cultural interactions. Based on this introduction, people can be more connected to their past and traditions by knowing and preserving this form of art and also preserve these traditions and customs in the process.

So such studies are necessary for recording and identifying ancient Iranian culture and customs, and identifying contemporary works.

\section{Aims and Objectives of the Study}

- Kerman carpet characteristic analysis;

- Analysis of symbols, designs, and patterns used in the Kerman carpet and their meaning;

- Analysis of the Kerman's people beliefs based on the symbols and designs used in their carpets.

\section{Method}

The methodology used for this Research is qualitative which mainly includes Ethnography fieldwork. Accordingly, the Tools and Techniques used for Data collection are:

- Informal, In-Depth, and Open-Ended Interviews with the help of a partially structured interview guide.

- Participants' Empirical Observations. 


\section{Research Theories}

The current study is quantitative and is not concerned with approving or disproving theories. The final results are gathered by the researchers' analysis of other texts, documents as well as field research.

\section{Research Questions}

- What are the characteristics of the Kerman carpet?

- What are the symbols, designs, and patterns used in the Kerman carpet and what do they mean?

- What are the beliefs of Kerman's people based on their carpet designs and symbols?

\section{LITERATURE REVIEW}

Hedayat (2008) completed research titled "Mirrors of Nature, Exploring the woven products from the tribes of Kohgiluyeh and Boyer Ahmad" and published this in the "Avai Dena" Journal of Cultural Research issues 13 and 14. He analyzes the ingredients, tools, and methods used for weaving such products by providing some examples (Hedayat, 2008).

"Each region's woven products as a symbol of each province's small culture expresses the spiritual qualities, as well as the embodiment of the material culture of their land", Says he while analyzing the symbols of these products.

Nasiri (2010) in the book Ancient Iranian Crafts talks about the evolution of the Iranian carpet weaving craft, their role in carpet evolution, and their motifs (Wolf, 2005)

Nasiri (2010) in the book "Immortal Legends of the Persian Carpet" points out the carpet's role in each family and this feminine art. And also considers the environment as an important factor in each carpets symbol and motif (Nasiri, 2010).

Razavi (2008) talks about the history of carpet weaving in the book "Carpet History - The evolution of the Iranian carpet weaving" which was published in 2014. This book consists of 10 chapters. He talks about Iranian carpet designs, motifs, and symbols in the 6th chapter (Razavi, 2014).

Arbabi (2013) wrote the book "Handiwork Workshop" in 2013, this book is consisted of 3 parts and includes 26 chapters.

He analyzes some carpet designs, personally designs some carpet motifs, and then analyzes the used symbols in these examples (Arbabi, 2013).

Yavari (2005) wrote the book "Basics of Iranian Carpet Recognition" in 2005. This book consists of 8 chapters. He talks about the position of colors and dyeing in the Iranian Carpet in the 5th chapter of this book. Subjects such as conflicts of colors, color harmonies, color associations with emotions, and varieties of colors (natural, artificial), etc. Then in the 6th chapter, he talks about the common designs and motifs of Iranian carpets. Based on his opinion Arabesque, Paisley, Stripped, "Gol Farang" (Rose), Herati (Fish, Jumble Fish), Garden, Medallion and Prayer-Nich designs are the dominant Iranian carpet designs (Yavari, 2005).

\section{AREA DESCRIPTIONS}

Geographic Location of the Kerman Province: The Kerman province is located in the southeast side of the Iranian Plateau between the 54 degrees and 21 minutes till 59 degrees and 34 minutes of Eastern Longitude and 26 degree and 29 minutes till 31 degrees 58 minutes of Northern Latitude of the Prime meridian (Kalantari, 2008). 
The maximum width of the province is 280 kilometers in the north and the minimum is 80 kilometers in the south. The medium width of the province is 250 kilometers and the distance between its northern and southern limits (The province's length) is estimated at around 660 square kilometers (Iranpor, 2012).

The Kerman province by occupying around 11 percent of Iran's soil after Khorasan's divide is the biggest province of Iran (Nasiri, 2010). Kerman city as the capital of this province with the coordinates of 50 minutes and 57 degrees of Eastern Longitude and 17 minutes and 30 degrees of Northern Latitude is placed in the heart of the Kerman plain which has an expanse of 1100 square kilometers. Based on the latest Country divisions the Kerman province has 16 counties, 45 sections, 57 cities, and 142 villages. The population of this province in 2016 based on statistics from the Statistical Center of Iran was equal to 3,164,718 people.

This province has more than 660 registered national monuments and is one of Iran's historical provinces. The Kerman province has 6 registered monuments in the UNESCO World Heritage Site which makes them Iran's leading province in this respect. This province also has claimed first place in the non-oil exports of the country for several consecutive years (Zang, 1991).

Geographic Location and Political Divisions: Kerman province is located in the southeastern part of the Iranian Plateau. This province leads to southern Khorasan from the north, Yazd and Fars provinces from the west, Hormozgan from the south, and Sistan and Baluchestan province from the east. The area of this province is equal to 180726 square kilometers. This province in the old country divisions was Iran's 8th province and also included the Hormozgan and Yazd provinces. The highest population of Iran's Zoroastrians lived in this province and this area's Sadeh celebration is recorded in the List of National Rites (Por, 1991).

The Climate of Kerman: The Kerman province has a climate variety of hot, humid, dry, and temperate mountainous. The long periods of hot weather in Kerman are notable. The maximum heat in the Kerman which surpasses 50 degrees Celsius happens in the Shahdad area (Kalantari, 2008).

Economy: The Kerman region because of its high mineral potential has many possibilities in creating industries dependent on mineral productions which some of these mines are among the richest mines around the whole country. Until this point, more than 150 mines have been recognized in this province. These mines, in creating small and big industries dependent on them, can have an important role in industrial planning and provincial improvement (Vaziri, 1997). This province based on geology and mineral resources has a special place in a way that large parts of different geological formations have happened in this place and that's why most mines of this province belong to the old times.

Industries and Mines: The Kerman province's Industries are divided into handmade and mechanized industries. The handmade or manual industries include shawls, Pate, and cashmere. The mechanized industries are divided into the three categories of the small, medium, and large workshop from which you can name cement, housing, food and dairy, beverages, sugar, coal, and copper that has worldwide fame. The province's mines play an important role in providing the countries needed raw materials. Iron-filled mines in Sirjan, coal, copper and other metals spin Kerman and Iran's wheels of industry. The coal mines provide a part of Esfahan Steel Company's needs. The Rafsanjan's Sarcheshmeh copper resources which are based on expert certification are among the riches and purest copper mines in the world, are among Kerman's special economic characteristics. 
Babak city's Midock copper mines, Baft County's Jiroft and Kahnuj Chromite mines are also among Iran's important chromite mines, and Kahnuj's Titanium mine is the only mine of this metal in Iran. Faryab mines in the Manoojan country are also of great importance (Bastani, 1993).

Farming: The Kerman province is the largest producer of pistachio in Iran. The Anar, Sirjan, Rafsanjan, Zarand, and Ravar counties are among the largest production centers of pistachio in the world. Akbari pistachio as the highest quality pistachio is a production of the Anar County. Bam County has the highest quality of dates in the world and is also the biggest producer of dates in Iran. The highest cultivation area of walnut in the country is in the Baft County which based on production this county is placed second in the country, Kerman's Caraway also has international fame (Golab \& Sir, 2011). But overall the most important crops of this province are Wheat, Barley, Potato, Pistachio, Henna, Woad, Caraway, Cotton, and Sugar Beet. In this province alongside Citrus and beat cold products such as Walnut, Almonds, Pears, Peaches, Cherries, Plums, and Apple Trees are produced (Zende, 1998).

Antiquities: Analysis shows that until now 449 antiquities have been registered in this province. The aforementioned antiquities include chambers, passes, religious buildings, tombstones, public showers, enclosures and pathways, mosques, water cisterns, and old houses and mansions (Vaziri, 1997).

\section{METHODS AND TECHNIQUES}

Clifford Geertz's Symbolic-Interpretive Anthropology Approach: Symbolic and Interpretive Anthropology is the study of symbols in their social and cultural context, which was brought about in the 1960s and progressed through the 1970s. These symbols are generally publically shared, recognized by many, and could be words, customs, or rituals. Symbolic Anthropologists describe and interpret symbolic meaning in emic terms, meaning that they interpret the symbols in the context of the culture that they are studying. A symbolic anthropologist believes that culture can be found in the public performance of symbolic systems and that there is generally a response to these symbols. Symbolic Anthropology was created in contrast to structuralism. Symbolic and Interpretive Anthropology states that symbols are learned and shared. This means that most symbols can be recognized by the people in that culture and often by people in other cultures. It also states that symbols are vehicles of culture, meaning they hold cultural meaning and significance. Symbols also transmit meaning and communicate ways about how people should view the world and feel about the world. Clifford Geertz (1926-2006) the main key figure of Interpretive Anthropology was considered to be the world's most influential anthropologist of the second half of the $21^{\text {st }}$ century. Geertz argues in Symbolic and Interpretive Anthropology that "culture is not a model inside of people's heads but rather is embodied in public symbols and actions". Geertz also focuses on the meaning of the symbols: "Believing, with Max Weber, that man is an animal suspended in webs of significance he has spun, I take cultures to be those webs, the analysis of it to be therefore not an experimental science in search of law but an interpretive one in search of meaning" (Geertz, 1973).

\section{Kerman Carpet}

Kerman carpets are one of the traditional classifications of Persian carpets though the term sometimes describes a type of carpet that may have been made elsewhere. Kerman rugs are prized for a wide range of designs, a broad palette, the use of natural dyes and fibers, great tensile strength and abrasion resistance, and expert color combinations. Typical manufacturing used an asymmetrical knot on cotton foundation, but rare examples may include silk or part silk piles, or 
silk foundations with the wool piles. Designs and motifs of the Kerman region: Because of the tremendous demand for rugs produced in Kerman and the complex demographics of this demand, a surprising variety of styles and designs were produced. Some Kerman rugs were woven explicitly for monies buyers from the West, some for local consumers with very different tastes.

Damask Rose is the most popular motif in Kerman rug designs, particularly in "Sabzikar Ravar" and "Gol Sorkhi" (Red Rose) rugs. Other well-known motifs are "Ghab Ghora'ani", "Setooni", "Ghabi", "Kheshti", "Saraam Atiyeh", "Jangali", "Shekargah" and "Lachak-Toranj". Kerman antique carpets often use the Toranj motif border of margins and narrow lines. Floral patterns woven into Kerman carpets in the 19th century are derived from the patterns of Kerman shawls, also made in Kerman at this time. A distinct variation of Kerman carpets is the Lavar or Ravar Kerman. These carpets were produced in Ravar village next to Kerman city in the northern region and are known particularly for their fine weave and elegant, classically derived design of allover and central medallion formats. Most Ravar or Lavar Kerman carpets include a signature, either that of the weaver or the person for whom the carpet was woven.

\section{RESULTS AND DISCUSSION}

The hand-woven Kerman carpets are filled with designs of philosophical worldviews and the spirituality of their creators alongside their simplicity. The artists alongside using natural or imaginary elements pictured effective phenomena in human life including historic events, natural accidents, architecture, etc. with a unique skill and expertise. Sometimes the designs and patterns of the Kerman Carpet are spiritual and inspired by the supernatural and sometimes are natural and earthly. No matter what each of their designs' reflects a message. For example, the Arabesque Design (A.K.A The Eslimi Design) is inspired by the movement and maze-like nature of plants, animals, trees, and overall natural designs. The Overall flower design is inspired by flowers, plants, tree branches, and leaves, and animals. The Bush design is a representation of the Cypress tree. In places without trees such as the desert and arid climates, people used to represent such climates in their handiwork and hand-woven crafts. The Hunting design includes different animals such as gazelle, wolf, lion, deer, leopard, and many types of birds. Also in this designs tree branches and flowers are used which give the Hunting design a beautiful and sweet look. And sometimes in there are designs of humans hunting the said wild animals.

Overall many different symbols, designs, and patterns can be seen on the Kerman carpet in the forms of Herbal, Geometric, Mythical, Animalistic, Visual, Natural, and Religious, and Colorful elements.

\section{Herbal Symbols}

Plants and trees in Iran have always been in the center of respect and attention and have had a special place for themselves and even in times became holy.

In the meantime, some plants and trees have turned into symbols based on characteristics such as beauty, lushness, fruitfulness or fruitlessness and or some mixed specific concepts and with the Persian culture. From which the Plane, Weeping Willow, Cypress, etc. can be mentioned.

Plane tree

The Plane is one of the greatest and longest-living trees of Iran. The Plane tree is so tall and upright that it can be seen from a long distance. The Iranian shepherds knew the Plane tree as the King of trees. But the Plane's greatness is not its only reason for holiness. The Plane sheds its skin every year and its strong branches take on a bright green color. This yearly rejuvenation of the Plane gave it unique holiness. Because maintaining youth is one of the main conditions of 
fertility and fruitfulness and as a result, the Plane is a representation of eternal blessings. Since people usually give ancient beliefs a new coat of paint to preserve and maintain them, the same has happened to the Plane tree, and based on the belief of some people there is an Imamzadeh (Shrine of the sacred person) buried beneath each holy and old Plane tree. The existence of any truth behind this belief is not known, but the important fact is that the holiness of a Plane is preserved using such methods and its design shows off itself on the Kerman Carpet.

\section{Willow tree}

The Willow tree in the Persian culture is a symbol of joyless love and even sometimes is a representation of grief. This tree is an automatic reminder of a heartbroken lover and shows their pain and grief. In some beliefs, the Willow tree is known as a humble tree and as a representation of a humble human.

\section{Cypress}

This tree is the symbol for immortality or life after death and that's why it's usually found beside graves. Because the top of this tree is bent and is obedient towards the wind, among some Muslims it's a symbol of the obedience of Muslims towards Sharia (Tashakori, 2001).

Sometimes the Cypress is known as a symbol of Iranian perseverance and pride. After the entrance of Islam to Iran, the Cypress tree is depicted with a broken top in paintings. It is said that this depiction of the Cypress tree in the paintings of time where a method from the Arab's to show the destruction of the Iranian strength after their attack. Also sometimes this tree is a symbol for the Garden of Eden. Overall in most Iranian art and also the Kerman Carpet, the symbol of a Cypress tree is used.

\section{Geometric Symbols}

A collection of regular geometric shapes such as circles, squares, and triangles and or mixed shapes such as checkered, six-pointed stars, Chalipa (cross), etc. are the main geometric symbols of the Kerman carpet.

\section{Square}

Square is a symbol for earth against the sky and also is a symbol of the whole world. The square is a reminder of the number four which is the representation of divine perfection. A square base on its shape is a representation of posture and firmness, stillness, and stability and as a result, can be a symbol of laws and justice that look at all under one, and also it can be a symbol for the place. The same way that circle is a symbol of time. Square is a symbol for the four main directions. Square is not a shape confided to symbols and this mysterious and stability-oriented shape alongside the rectangle from which it has been born has been the source of inspiration for many artists throughout the years which is also a fact in the Iranian carpets. Because most Iranian houses are four square, the Iranian carpet is woven the same way.

\section{Circle}

Circle alongside the meaning of perfection is a symbol for the creation of the world and also the concept of time. Moments are represented after each other and are continuous and circular. In Persian mythology circle, sphere and hemisphere are all symbols of Mitra (Religion before Zoroastrianism in Iran) and have a great share in symbolism. Sometimes in a more direct meaning 
circle is a representation of the cosmic sky epically when it's in confluence with earth and they are harmonious.

\section{Triangle}

The Equilateral triangle is a symbol of coordination and proportion and also sometimes can represent the meaning of the earth. If the vertex of the triangle is upwards then it's a symbol of fire and the male sex and if it's downwards a symbol of water and the female sex. The triangle shows the meaning of fertility. Also in Persian Mythology, the triangle is the symbol of Anahita.

\section{Chalipa (cross-Swastika)}

This geometric symbol which is solid atop a square system has many different meanings and overall is the symbol for the sun. "Chalipa in any form and shape is a symbol of the infinite passage of time and its procedure of birth and death, existence and naught joint and break and this is the wheel of time that spins and breaks everything with no beginning and no end. This symbol in the Aryan culture stands for good luck and rebirth" (Bakhtor, 2001).

\section{Arabesque (Eslimi)}

The name Eslimi is taken from the term Islamic, this design is one of the Parthian and Sassanian artist's creations. The Arabesque design which has a fundamental role in decorative motifs of Iran includes circular duplicate maze rotations that are often symmetrical which can be a reminder for the twists of a plant's stem.

In other words, the Arabesque design is a kind of pattern which includes complex lines, different curves, and arcs that are depicted in decorations, inscriptions, and other artistic works. In Carpet weaving, the Arabesque design is sometimes used as the main design and sometimes alongside other designs. Different types of Arabesque design which are used in the Kerman Carpet include Serpent Arabesque or Dragon's Mouth, Scroll Arabesque, and Elephant Trunk Arabesque.

\section{Mythological Symbols}

Mythologies are present among all nations and folks and are a part of ethnic, native, and national culture. Mythological beliefs whether in urbanized nations and communities and or scattered tribes can be seen in the form of traditions. Mythologies retell the ideologies of the nation that they originally belong to, such as the perspectives towards good and evil, the Gods, and the bravery of heroes and mythical creatures.

Mythology is the creation of human thought and belief and is one the main creating factors of the ethnic culture of early societies and is counted as a part of the folks' identity that satisfies the spiritual and material needs of man; based on this mythology can be the determiner of the social life of a nation and folk. Mythologies manifest in symbols. There are also many mythological symbols in the Kerman Carpet which we will describe some of them right here.

\section{Tree of Life}

The tree of life is the secret of "The Axis of the World" and is an evergreen tree with fruits that bear eternity and immortality and the existence of all trees. Usually, this tree is shown as a tree with many branches, representing the idea that all of earth life is connected. In another interpretation, the tree of life is a symbol of resurrection and immortality. This tree is probably the Haoma tree of Zoroastrianism. This symbol is used very frequently in carpet weaving. 


\section{Living Rock}

In some carpets of Kerman, we see a rock-like design that usually is mixed with human or animalistic faces. It seems that the human and animalistic designs available in these rocks are a symbol of the live and dynamic psyche of rocks which cannot be presented directly and so the combination of what is living and current and what is hard and inflexible was used as a solution.

\section{Winged Humans}

The role of winged humans in Iranian arts has a long history. "Angels are winged messengers that create a connection between God and humankind." (Hall, 2004).

The combination of the Human body with enormous wings can be a symbol for "HumanGod". The presence of angels as a mediator between the divine court and men who uses the tool of words as a mean of transition and the presence of humans, the greatest of creations, who are ornamented with the power of words has caused the role of angels to be created as a mixture of the human body and bird-like wings.

\section{Demon}

In Persian mythology, demons are imaginary and fictional creatures with unnaturally strong, ugly, and terrible but human-like bodies. It is presumed that demons have tails and horns. The picture of demons are sometimes used in the Kerman carpet designs and sometimes these patterns and pictures are created by a combination of other elements such as the combination of a human body with the legs, hands, and or head of other animals like dogs, monkeys, wolfs, etc. that overall they are a symbol of the predatory traits of this hybrid or demon creature, as such it can be said that demons are symbols of the ugly temperament of men depicted in a human-animal manner.

\section{Dragons}

In ancient Iran, just like other ancient countries (Egypt, Babylon, China, and India), there were many legends about dragons. Although dragons in lands such as India and Babylon were symbols of droughts, darkness, and destructive floods, in Iran there were symbols of moral evil and vices. In Avesta (The holy Book of Zoroastrians there are many myths about dragons that easily compared them with a notorious historical character that had a name like AjiDahak (dragon) (Coyaji, 1974).

In Iranian culture to fight with a dragon is to overcome your problems, killing dragons means the struggle between light and dark and the human domination over the inciting self and selfcontrol. Although nowadays many people believe that there is a connection between dragons and fire but based on the belief of some people the main element of dragons of water. This water-like bond fundamentally distinguished the dragon from other multi-shaped mythical creatures. Even the desert-based folk emphasize this point and their dragons are usually at the bottom of wells (It's important to say that a vast part of the Kerman province and dry and desert). The bottom of a well was usually seen as a dragon's eye (Warner, 2007).

Phoenix

Phoenix is the most famous Iranian legendary-mythical figure. It has an important role in many stories of the Shahnameh (Ferdowsi Poetry Book). And it is well known and used in Iranian arts. Its living place is the mythical mountain of Qaf. In Ferdowsi's Shahnameh book the Phoenix has a God-like and an Evil visage because all supernatural creatures in the eyes of the followers of Dualistic Cosmology are opposite twins. But based on Iranian fictional and cultural literature such as Attar's The Conference of the Birds, the Phoenix is a symbol for thirty birds who to discover 
the answers to their mystical questions take a long journey in the path of knowing the truth and as they reach the holy phoenix, they find out that the seeker and the sought are the same, because they were thirty seeking birds and their sough was the phoenix.

\section{Animalistic Symbols}

The designs of some Kerman carpets are taken from Iranian culture and literature, designs that depicted texts some of which included stories from animals and advice from their lives. These versions introduce animals as ethical symbols. Sometimes animals are used as symbols of superiority and power (Yahaghi, 2011).

These Symbolic animalistic symbols in the Kerman carpet include Lions, Cows, Goats, and many types of Birds.

\section{Cow}

The cow is a symbol of earth and the force of nature and is associated with the moon and rain clouds. The cow in Iranian mythology is a symbol of the battle between light and dark, good and bad.

In the after Islam Iran, sacrificing a cow based on the belief of philosophers of ethics is for killing the self-cow and ridding yourself from reconstructed lust and sensuality. Even after Islam the mythical meaning of a cow has still conserved itself in the people's folk culture.

\section{Rooster}

The rooster had a special place in ancient Iran and we can repeatedly see this position and role of the rooster in everyday life in the writings and beliefs of the authors of ancient Iran whether before or during the Islamic era. The rooster has always been introduced as a holy bird. The rooster is the representative of Sraosha (a guardian angel from ancient Iranian belief) in the world. He sees the dawn from the far and informs others. Based on this it is believed that the Rooster is the enemy of the sleep demon "Boshasia" and Boshasia is a demon that prevents people from getting up in the dawn and saying their praying towards the dawn and before the sun is fully up. The rooster sings by seeing the dawn, the arrival of the day, and following that the rise of the sun. The demon Boshasb (Boshasia) is the demon of sleep and excessive laziness and based on ancient Iranian belief, the rooster is the watchman of the night and with the arrival of dawn fights Boshasia.

\section{Lion}

In Iranian thought, the Lion has always been a symbol of pride and valor. The symbol of monarchy and the sign of bravery. In works of art, he stands tall alongside kinds, and his statue is installed alongside the graves of champions and heroes. Throne of Goddesses is on his shoulders and the Throne of Kings on his paws. The lion is a guardian of temples and his looks carved on the stone is a protection force worn as a necklace. The lion is one of the most important fundaments of Mithraism. The heavenly lion is the symbol of summer and has a fiery nature.

The lion is present in many Iranian carpet designs including the Kerman carpets and most of these shapes, the lion is a symbol of the glory and majesty of monarchy, Iranian power and greatness, Symbol of bravery, and sometimes symbol of power, greatness, and bravery of the first Shias Muslim Imam because the Shias know Imam Ali as the lion of God and God's Sultan on earth and because the majority of Kerman's people are Shias this symbol is used on many Kermani carpets. 


\section{Peacock}

The peacock has a special place in Iranian culture and because of all the vast meanings hidden in it has become a divine and religious symbol with a place higher than apparent beauty. The peacock is sometimes the symbol of beauty, sometimes the symbol of shame, sometimes the symbol of the monarchy, and sometimes the symbol of boasting. Some people believe that the peacock knows the devil and can prevent it from entering the house or place. So based on this many people have drawn the shape of a peacock atop the doorway of houses and mansions.

\section{Gazelle}

The gazelle is a symbol of the lover and shows oppression, innocence, and spiritual love. In other words, the gazelle is an allegory for a human that has passed virtual love and has reached true and divine love.

\section{Visual Symbols}

In recent visual carpets of Kerman, you can find pictures of kings, great Iranian and foreign characters, and religious leaders. The most used pictures are of Imam Ali (The leader of the Shia Muslims), Khayyam (Iranian Famous poet) and his lover (symbol of love), Hafez (famous 14thcentury poem - a symbol of love and mysticism), King Abbas, King of the Safavid era, etc.

\section{Natural Symbols}

Nature and our outlook towards it have always been integral in the framework of the special aesthetic of Iranian art. Flowers, Gardens, Trees, Water, Fountains, Hills, Mountains, the Moon, and the Sun have been integral parts of the Kerman carpet designs. In this way one of the natural elements of the Kerman carpet is the sun which is famous as the Sun corner design or Ms. Sunshine and has an ancient history, this design is very common in carpets and is used in broken and curved and is used by rural, nomad and urban weavers of Kerman.

One of the other important natural designs of the Kerman carpet is water. Water is the fundamental element of life and is a symbol of life, death, the secret of creation, purity, and redemption, fertility and growth, resurrection, and metamorphosis. Water is the element that creates the relationship between humans and nature. In Iranian arts water is shown with silver color and using the silver metal itself, and the purpose of using actual silver is to create light, the reflection of light, and more realistic rays of light that create ad mystical trade with the observer's soul. Generally, water is the symbol of prosperity and where there is water there is greenness and freshness.

\section{Religious Symbols}

"In Iranian painting, humans don't have a shadow the same way that angels don't have one. Everything is light, the role of humans is separate and heavenly without a base and free of the Wight and volume of real everyday life. This allegory of humans, angels that were known as Amesha Spenta (Iranian angels) in the thoughts of Mazdayasna and Yasht hymns, is one of the clearest facets of the Iranian soul in literature and paintings." (Agdashlo, 2005)

In human designs what sometimes catches our eyes is the usage of the holy aura. This aura (God the Zoroastrians) is seen upon the human bodies and also birds and animals that by considering the effects of the Islamic thought system could show the holiness of all creatures and their equal position in front of God. But over time, this aura only surrounded the head of the saints and became a symbol of the shining of the divine light from the divine character. Pictures 
Infallibles especially Imam Ali, Imam Hussein, Imam Reza, etc. with their holy aura are the main designs of many Kerman carpets.

\section{Symbol of Color in Kerman Carpet}

Human society is filled with symbols that have been formed over time and found a special place in human life. Symbols are formed based on habits and geographical beliefs and without a doubt are rooted in the thoughts of the people of an area. In the meantime color as a symbolic attribute has found a very special place in the culture and art of each civilization. The selection of color is dependent on factors such as geographical location, cultural background, religion, etc. In the past colors were representatives of welfare and evil; sometimes as a reminder of the Devil and evil and impurity and sometimes as a sign of holiness and purity and good. Also, colors in combination with different forms were used to protect humanity from the forces of evil.

Color in the Art of Islam is an important and effective element. In Iranian and Islamic mysticism even the levels of the mystic's Soluk and or his mystical mood each have a specific color. In Mithraism, Mazdayasna and Manichaeism lightness have Great value and auspiciousness. After them in Islam, God is called the light of Skies and Earth, and the value of this phenomenon is once more revealed.

Based on this in Iranian art, color is not just one simple attribute (quality) and each color is a symbol. Colors are symbols of love and the placement of the sun in the sky and ancient Iranians believed that colors of the world have a Mino (heavenly) origin and have descended from another realm. This subject is also true about the colors used in the Kerman carpet and each of these colors have their unique meaning, of course nowadays the main drive behind choosing the color of a Carpet is the color of the other furniture inside the buyers' house and people believe that there should be a connection between the carpet and the other furniture, for example having white-pink furniture and a navy blue carpet is wrong. Generally, the Kerman carpet is the most color carpet in Iran and the meaning of the most used colors in these carpets are:

\section{Red}

In Iran red is a symbol of fire but among Shias Muslims and in the religious ceremony of Ashura (The day of the martyrdom of Imam Hussein) is the symbol of martyrdom. In the Iranian-Islamic culture, the red rose is also a symbol of martyrdom.

\section{Yellow}

Overall the color yellow is one of the bright colors. This color is a metaphor for the sun, the color of eternity and immortality. This color is partially the symbol of holiness and usually, the aura surrounding the heads of saints is shown with this color. Sometimes this color is converted into gold.

\section{Blue}

In Iranian thought, the color blue is the symbol of purity and spirituality and sometimes the symbol of wisdom. This color accompanies intelligence, discovery, and Intuition. It makes sense of Insight, illumination, and thought. Blue is an insight color that creates a transcendental mood in humans. In the architecture of Islamic mosques blue and cyan colors are frequently used. 


\section{Brown}

Generally, the color brown is the symbol of earth, being healthy, support, safety, comfort, trustworthiness, senility, quality, and honesty. Milky, beige, ivory, light brown, smoky brown, chocolate brown, dark brown, and burnt brown are the spectrum of brown which are used in the Kerman carpet.

\section{Green}

Green is the symbol of freshness, balance, and rebirth and just like spring, it refreshes the body and the soul.

Based on culture the color green has many and sometimes contradicting meanings. In some cultures, green is the symbol of hope and progress meanwhile in others it's a symbol of death, diseases, and the devil. But generally, in most cultures, it's a reminder of nature. In Islam, it's believed that paradise is a lush and green place which is one of the reasons for the usage of green in the Islamic culture. This color especially among Shias Muslims is a symbol of being a Sayyid (grandchildren of the Imams and the Prophet of Islam) and obedience to Imamate and Province. In the past Sayyids were specifies by green hats and shawls.

\section{Navy Blue}

Navy blue is a very cold color. Using such colors as navy blue and black creates a sense of pride and self-confidence as a result of that.

\section{Cream}

Although this color those not have as many meanings and symbolic values as the other colors but based on its joyfulness and aliveness, the cream is used by Kerman carpet weavers and is highly adaptable with the house decoration of the people of Kerman.

\section{Cyan}

Cyan is a collection of colors between the spectrums of green and blue with characteristics like bringing good luck and refrain from bad comments, etc. Cyan is known as a color with positive values among the people of Kerman.

\section{CONCLUSION}

The Kerman carpet is a symbol of the Iranian carpet and a part of this country's cultural identity to the world.

Kerman carpets have had many different symbols and patterns in each different era. Therefore, analyzing carpets from different eras can lead to a deep understanding of the traditions of the people of that time and also can help transfer their cultures.

The patterns and designs of the Kerman carpet have been subject to many changes in history just like the other traditions and cultures of this land. In some periods, pages of history were woven into the Kerman carpets which were an illustration of the Iranian people's art in the form of carpets and rugs. Each pattern and design found on the different Kerman carpets can be representatives of different and unique characteristics, for example:

Sometimes the designs of the Kerman carpet are messengers of the climate and geographical environment of the region. From this point of view, the designs of the Kerman carpet are the artist's look towards his surrounding climate and nature. And sometimes their designs are 
filled with philosophical and mystical worldview and a show of its owner's spirituality that shows itself with ultimate simplicity.

And sometimes they talk about the beliefs of their people and the Kerman carpet is a reflection of the old beliefs and traditions of the people of that region which have evolved in the coming ages. This form of art is created according to the spiritual and mental needs of people.

And sometimes the Kerman carpet's designs and symbols have historical roots and its arrays date back to before Islam.

In conclusion, the Kerman carpet designers illustrated natural and or imaginary elements with the language of symbolism and unique skill alongside impactful events in human life including historical events, natural incidents, architecture, etc. Therefore this form of art is just like a mirror that reflects the culture of the Iranian society and specially Kerman.

\section{Suggestions}

- Creating an Anthropology Museum in the field of carpets and carpet weaving based on traditional culture for tourists visiting Kerman;

- Using the designing and carpet weaving masters as the faculty to transfer their knowledge to the next academic generation;

- Setting up cultural exhibitions and conferences, and inviting the residents and tourists to take part in such conferences to revitalize, preserve and transfer the Native culture, especially the carpet weaving industry;

- Methods of expanding tourism to sell handicrafts especially carpets to tourists; to liven up the arts and industry;

- Financial and emotional support for designers and weavers of Kerman carpet for engorgement;

- Doing more research in the field of Kerman carpet patterns and designs.

\section{REFERENCES}

Agdashlo, I. (2005). Old Painting, New Painting, Tehran: Artist Career Quarterly ("Herfeh Honarmand"), Number 1.

Arbabi, B. (2013). Crafts Workshop (Weave), Tehran: Iran Textbook Publishing Company.

Bakhtor, T. N. A. (2001). The Sun Dial, or the Mehr Dial, Tehran: "Attai" Publication.

Bastani, P. M. I. (1993). Congress' Shadows, Tehran: "Arghavan" Publication, First Print.

Coyaji, J. C. (1974). Rites and legends of ancient China, Translated by Jalil Dostkhah. Tehran: Franklin.

Geertz, C. (1973). The Interpretation of Cultures: Selected Essays, USA: New York; Basic.

Golab, Z. M., \& Sir, M. (2011). Kerman in the Mirror of Tourism, Kerman: "Markaz Kerman Shenasy" Publication.

Hall, J. (2004). Eastern and Western Art (Icon Editions), translated by Roghayeh Behzadi, Tehran: "Farhang Moaser" Publication. 
Hedayat, A. (2008). Mirrors of Nature, Exploring the woven products from the tribes of Kohgiluyeh and Boyer Ahmad, Avay Dena Quarterly, No. 13-14, Culture and Islamic Guidance Publication.

Iranpor, M. (2012). Kerman, Pearl of the Orient, "Gova" Publication, First Print.

Kalantari, K. H. (2008). Analysis of Kerman Province Geography based on Natural Matters, Kerman: Kerman Studies Publication (Kerman Shenasi).

Nasiri, M. J. (2010). Iranian Carpet. ’Parang" Publication.

Por, A. A. (1991). Geography and Construction of Kerman City, Tehran: University Jihad Central Office Publications.

Razavi, H. F. A. (2008). History of Carpet: The evolution of carpet weaving in Iran, Tehran: Published by Ministry of Culture and Islamic Guidance.

Razavi, H. F. A. (2014). Iranian Carpet, Tehran: Office of Cultural Research.

Tashakori, F. (2001). Symbolization in Islamic Art, Tehran: Encyclopaedia Islamica.

Vaziri, A. A. (1997). History of Kerman, Kerman: Elm Publication.

Warner, R. (2007). Encyclopedia of World Mythology, Translated by Abol Ghasem Ismailpor. Tehran: "Ostoreh" Publication.

Wolf, H. (2005). Iranian Traditional Hand-Woven Art, Translated by Sirous Ibrahim Zadeh, Tehran: "Elmi \& Farhangi" Publication.

Yavari, H. (2005). Recognizing Iran's Rugs and Rug-likes, Tehran: "Azar" Publication.

Yahaghi, M. J. (2011). Analyzing Visual Symbols, The Journal of Epic Literature, Year 11, Spring and Summer.

Zang, A. A. (1991). Geography and Kerman City Planning First Volume: Old Tissue and Planning, Tehran: "Etelaat" Institute.

Zende, D. H. (1998). Comprehensive Travel Guide for Kerman Province, Tehran: "Irangardan" Publication, First Print.

\section{Copyrights}

Copyright for this article is retained by the author(s), with first publication rights granted to the journal. This is an open-access article distributed under the terms and conditions of the Creative Commons Attribution license (http://creativecommons.org/licenses/by/4.0) 